\title{
Ethanol Content Determination in Medicine Syrups Using Headspace and Multidimensional Heart-Cut Gas Chromatography Coupled to Mass Spectrometry
}

\author{
Lilian R. Batista ${ }^{\circledR * a}$ and Nelson R. Antoniosi Filho ${ }^{a}$ \\ ${ }^{a}$ Laboratório de Métodos de Extração e Separação (LAMES), Instituto de Química, Universidade \\ Federal de Goiás, Campus Samambaia, CP 131, 74001-970 Goiânia-GO, Brazil
}

\begin{abstract}
Despite the efforts of the pharmaceutical industry to reduce the ethanol content in medicines, many of these products are still commercially available. These medicines must be monitored by quality control techniques using accurate method. Therefore, this study proposes to develop and validate an analytical method for ethanol quantification in adult and pediatric syrups, in order to guarantee the safety of medication certificates. For this, headspace multidimensional gas chromatography (heart-cut) coupled to mass spectrometry (HS-MDGC/MS) was used. The method was validated according to the norm established by National Agency of Sanitary Surveillance (ANVISA) presenting limit of detection (LOD) of $0.03 \%(\mathrm{v} / \mathrm{v})$ and limit of quantification (LOQ) of $0.06 \%(\mathrm{v} / \mathrm{v})$ ethanol, excellent selectivity and the recovery values (accuracy) were between 96.71 and $101.38 \%$. Ethanol concentrations in commercial medicines syrups varied from 0.06 to $8.83 \%$, which makes evident the need to control the syrup producing industries.
\end{abstract}

Keywords: alcohol, analytical validation, multidimensional chromatography, medicated syrup, quality control

\section{Introduction}

In recent years, the pharmaceutical industry has grown, as well as the demand for more effective medicines. Considering oral medications, syrups are among the most common liquid dosage forms, and the active principle is available to be absorbed more rapidly. ${ }^{1}$ According to the National Formulary of Brazilian Pharmacopoeia, ${ }^{2}$ syrup is a high viscosity liquid formulation containing more than $45 \%(\mathrm{~m} / \mathrm{m})$ of sucrose in the composition to improve the palatability. The syrup is also composed of flavoring agents, antimicrobials, sweeteners, preservatives and thickeners or stabilizers. This type of preparation is quite effective due to the difficulty of children in swallowing capsules and tablets, however, each compound concentration to the syrup are not reported in the package leaflet. ${ }^{3}$ In addition, not all components are defined as an active substance or an excipient in the medicament. Substances, such as organic solvents, have negative effects on the patient and offer no therapeutic benefits. ${ }^{4}$

Almost $80 \%$ of pediatric medicines are syrups, solutions or emulsions and contain ethanol (2.3 to 20\%). ${ }^{5}$ Ethanol is used both to increase the solubility of some

*e-mail: lilianribeiro_18@hotmail.com ingredients and as a preservative due to antimicrobial activity. ${ }^{6}$ Pharmacological studies in children with acute alcohol intoxication show that ethanol absorption is faster than reported in adults. ${ }^{7,8}$ Ethanol administration may cause hypoglycemia and effects on the central nervous system, including muscular incoordination and behavioral changes. ${ }^{5,9}$ Moreover, prenatal exposure to ethanol may still have an influence on the child's development, including hyperactivity, attention and memory deficits, social and emotional development problems. ${ }^{10,11}$ Although the lethal dose is 5 to $8 \mathrm{~g} \mathrm{~kg}^{-1}$ in adults and $3 \mathrm{~g} \mathrm{~kg}^{-1}$ in children, morbidity and mortality may occur with other medication interaction. ${ }^{12,13}$

Due to the harmful effects of exposure to ethanol, an accurate method for quality control of these drugs is required. However, there is no Brazilian regulation to determine the ethanol content in liquid formulation and there is little research reported in the literature. Most methods require complicated sample preparation, for example, involving the oxidation of ethanol by nicotinamide adenine dinucleotide (NAD) forming acetaldehyde, reduced NAD $(\mathrm{NADH})$ and a proton. Quantification was done by detecting NADH using UV spectrophotometry. ${ }^{14}$ Other methods mainly use gas chromatography due to the volatility of organic solvents; however, they require a long run times, 
analytical preconcentration processes, and present low reliability when detecting a component in the presence of others of similar physicochemical properties. ${ }^{4,5,15,16}$ Huzar and Wodnicka ${ }^{5}$ analyzing ethanol in medical syrups applied a headspace method with two chromatographic columns, nevertheless, it was necessary to distill each drug for accuracy and this requires a large amount of sample. This sample preparation does not guarantee total extraction of the analyte, compromising the quantification. Organic composition of liquid medicaments used by the infantile public was also made by nuclear magnetic resonance (NMR), an extremely expensive technique that requires specialized training for data treatment. ${ }^{17}$

The search for better living conditions requires greater control over medication administration. The progress of science motivated by the demand for more specific and efficient analytical systems highlights the interest in the development of multidimensional chromatographic methods providing high resolution for analysis of complex samples. In this context, headspace method using multidimensional gas chromatography (heart-cut) coupled to mass spectrometry (HS-MDGC/MS) was developed for ethanol determination in medicated syrups for adult and pediatric use. In order to ensure the reliability of the results obtained, it was necessary to validate the analytical method used, as a guarantee of the quality of the measurements. ${ }^{18-20}$ National Agency of Sanitary Surveillance (ANVISA) prepared a guide for validation of the analytical methods corresponding to Resolution of the Collegiate Board of Directors (RDC) No. 166, 2017, ${ }^{21}$ which is selected for the analytical methods validation in the pharmaceutical industry.

\section{Experimental}

\section{Analytical standards and reagents}

Ethyl alcohol, isopropyl alcohol and sorbitol were analytical standard grade ( $\geq 99.9 \%$ standard for GC) purchased from Sigma-Aldrich-Merck KGaA, Darmstadt, Germany. Standard diluted solutions were prepared considering the therapeutic index from dilution of the respective storage solution of $10 \%(\mathrm{v} / \mathrm{v})$ ethanol in water and sorbitol. Raw materials for ranitidine hydrochloride syrup production are in Table 1 and were supplied by a small pharmaceutical industry located in Goiás-Brazil. All reagents were analytical grade.

\section{Syrups samples}

Seventeen liquid formulations used in this study were purchased locally in Goiânia, Goiás, Brazil. One brand was
Table 1. Formulation for syrup production

\begin{tabular}{lc}
\hline Organic raw materials & Inorganic raw materials \\
\hline Ranitidine hydrochloride $^{\mathrm{a}}$ & monopotassium phosphate \\
Carmellose 5000 (CMC RV 5000) & anhydrous dibasic sodium phosphate \\
Methylparaben & sodium chloride \\
Propylparaben & sodium hydroxide \\
Sodium saccharin & purified water q.s. ${ }^{\mathrm{c}}$ \\
Sorbitol solution $70 \%{ }^{\mathrm{b}}$ & - \\
Hydrosoluble liquid mint extract & - \\
Ethyl alcohol $96^{\circ} \mathrm{GL}$ & -
\end{tabular}

${ }^{\mathrm{a}} 16.80 \mathrm{mg}$ of ranitidine hydrochloride are equivalent to $15 \mathrm{mg}$ of ranitidine; ${ }^{\mathrm{b}}$ sorbitol solution $70 \%$ equivalent to $62 \mathrm{mg} \mathrm{mL}^{-1}$; ${ }^{\mathrm{c}} \mathrm{q}$.s.: quantum satis.

evaluated in two separate lots. Medicine syrups of several utilities such as cough syrups, stomach pains, syrups for influenza and multivitamin complexes were used. All syrups analyzed were adult and pediatric use, and some determined the age and dosage to be applied to the label or package insert.

\section{Analytical instruments}

\section{Optimization of sample extraction}

A $10 \mu \mathrm{L}$ aliquot of the sample or analytical standard was transferred to a $20 \mathrm{~mL}$ vial with aluminum sealing wax and septum for volatiles analysis via headspace. For direct headspace it was used: $90^{\circ} \mathrm{C}$ for heating the syringe, $100{ }^{\circ} \mathrm{C}$ for incubator temperature, 15 min incubation at $500 \mathrm{rpm}, 30 \mathrm{~s}$ of syringe purge using nitrogen gas at $1.2 \mathrm{bar}$ and $500 \mu \mathrm{L} \mathrm{s}^{-1}$ filling speed inside the syringe. In the split mode (1:20) $250 \mu \mathrm{L}$ of the steam was injected on the flame ionization detector (FID) detector-containing chromatograph.

\section{Instrumentation and conditions}

MDGC/GCMS-2010 multidimensional gas chromatograph (Shimadzu Corporation, Kanagawa, Japan) and an AOC-5000 autoinjector (Shimadzu) was used. The system consists of a gas chromatograph GC 2010 Plus, split/splitless capillary injector, flame ionization detector (FID) and flow and pressure automatic controller. MDGC also includes a second chromatograph coupled to a mass spectrometer (MS) model GC/MS-QP2010 Ultra, however, the split/splitless injector in the second GC was not used.

\section{Operational conditions}

The GC-FID (1D) oven temperature program was: initial temperature of $100{ }^{\circ} \mathrm{C}$ with linear ramp of $15{ }^{\circ} \mathrm{C} \min ^{-1}$ to $250{ }^{\circ} \mathrm{C}$. The carrier gas used was helium, 
with an initial pressure of $171.4 \mathrm{kPa}$, at a constant linear velocity of $20.0 \mathrm{~cm} \mathrm{~min}^{-1}$. The FID detector was maintained at $300^{\circ} \mathrm{C}$. The GC/MS (2D) oven was constant at $56{ }^{\circ} \mathrm{C}$ and linear velocity of carrier gas (helium) was $45 \mathrm{~cm} \mathrm{~s}^{-1}$. Mass spectrometer samples were analyzed in full scan mode with scanning speed of $20.000 \mathrm{amu} \mathrm{sec}^{-1}$ and $70 \mathrm{eV}$ in electron impact mode (EI) between 45 and $200 \mathrm{~m} / \mathrm{z}$. The interface and ion source temperatures were both at $250{ }^{\circ} \mathrm{C}$. Total run time was $10 \mathrm{~min}$. RTX-5 capillary column (Crossbond ${ }^{\circledR} 5 \%$ diphenyl/95\% dimethyl polysiloxane, $30 \mathrm{~m} \times 0.25 \mathrm{~mm} \times 0.25 \mu \mathrm{m}$ ) was employed in the first dimension and connected to a switching device with a NST 100 MS column (Carbowax polyethylene glycol, $30 \mathrm{~m} \times 0.25 \mathrm{~mm} \times 2.00 \mu \mathrm{m}$ ), installed in the second dimension. A switching device was used to control pressure (advanced pressure controller (APC)) and $100.6 \mathrm{kPa}$ pressure used allowed total transfer of the selected peak. All data were collected using MDGCsolution software (Shimadzu).

\section{Analytical method validation}

Quantitative analyses were performed using only the 2D column (GC/MS). Analytical method validation was conducted as described in Resolution RDC of the National Health Surveillance Agency (No. 166, 2017), ${ }^{21}$ which recommends the evaluation of the parameters of selectivity, linearity, accuracy/precision, limit of quantification (LOQ), limit of detection (LOD), as well as the robustness of the method.

\section{Selectivity}

Ranitidine hydrochloride syrup was selected and evaluated for the interferes presence. The purity of the ethanol peak and each component of the syrup (Table 1) were evaluated in order to verify the selectivity of the method.

\section{Linearity}

Ethanol quantification was done by the chromatographic peak area. To test the linearity and to observe if there is matrix effect in the quantification process, three different methods were used: calibration curve with sorbitol as solvent; calibration curve with water as solvent; and calibration curve with water and sorbitol $\left(62 \mathrm{mg} \mathrm{mL}^{-1}\right)$. Standard solutions were prepared in eight concentrations: from $0.025 \%(\mathrm{v} / \mathrm{v})$ to $10.0 \%(\mathrm{v} / \mathrm{v})$ ethanol. These patterns were injected in triplicate and the data were submitted to linear regression analysis by least squares method.

\section{Precision}

Inter-day precision (intermediate precision) was performed on two different days and evaluated by two different analysts. The intra-day variation test was performed on the same day by the same analyst. Ranitidine hydrochloride syrup was selected and the precision of the method was expressed by coefficients of variation (CV). At least 9 determinations were used, considering the linear range, that is, 3 concentrations: low, medium and high, with 3 (three) replicates at each level.

\section{Accuracy}

Recovery was determined by adding known amounts of ethanol standard directly into the sample. Three different concentrations within the concentration range of the analytical curve (low, medium and high) were studied. The accuracy of the method was expressed as percent recovery.

Limit of quantification (LOQ) and limit of detection (LOD)

The limit of detection (LOD) and limit of quantification (LOQ) were calculated by the relationship between the standard deviation $(\sigma)$ of the regression lines and the slope $(\mathrm{S})$ of the calibration curve. The equations $\mathrm{LOD}=3.3 \sigma / \mathrm{S}$ and $\mathrm{LOQ}=10 \sigma / \mathrm{S}$ were used, respectively.

\section{Robustness}

Samples were prepared and injected under optimized conditions. To show the ability to withstand small and deliberate variations ${ }^{21}$ the parameters of extraction time, linear velocity of the entrainment gas and temperature of the furnace were altered. The concentrations were analyzed by analysis of variance (ANOVA) and Tukey's test, to provide the method robustness.

\section{Statistical analysis}

The measurement uncertainties were estimated from analytical errors and standard deviations of the samples. The single-factor ANOVA variance analysis was applied to compare the quantitative results using the Tukey's test with a significance level of 0.05. Microsoft Office Excel was used for statistics at a significance level of 5\%.

\section{Results and Discussion}

\section{Headspace optimization}

The optimization of the extraction conditions was based on the maximum ethanol yield recovered from the sample. Two parameters were evaluated: syringe temperature and incubator temperature, maintaining the extraction time constant (15 min). By testing different temperatures, it was possible to compare the recoveries obtained in each of these heated parts using headspace system (Figure 1). The ideal temperatures for the syringe and the incubator 
were 90 and $100{ }^{\circ} \mathrm{C}$, respectively. Values near of the ethanol boiling point (bp $78^{\circ} \mathrm{C}$ ) did not show good recovery and on very high temperatures, there was loss of this analyte. Differently from that reported by Huzar and Wodnicka, ${ }^{5}$ which needed to distill the samples even using headspace as the extractor system, the results using an automated injection system without pre-treatment of the sample showed to be effective in quantifying all ethanol in each syrup, minimizing analytical errors due to sample handling.

\section{MDGC method development}

One-dimensional gas chromatography offers high peak capacity along with a diverse number of available configurations and detectors. However, when the samples studied present high complexity some overlapping peaks can appear due to its limited selectivity and sensitivity. ${ }^{4}$ The optimization of the carrier gas flow and temperature during the separation is necessary to obtain good results in the multidimensional separations. The temperature ramp applied in the first dimension directly influenced the peak width of the components eluted in 1D. This is because the elevation of the temperature above the ethanol boiling may have led to a rapid elution.

The influence of carrier gas flow on the MDGC system is very complex once the two columns are connected. Flow rates of the entrainment gas cannot be selected independently, that is, the selected flow rate should result in acceptable separation in both dimensions. This stage of pre-optimization of the chromatographic conditions, still without the heart-cutting process, allowed obtaining the highest possible chromatographic resolution in 1D for syrup analysis after headspace extraction. Temperature programming improved the high-retained peak detection and made the analysis faster (10 min).

A chromatograph equipped with a FID in the first dimension is coupled to another chromatograph containing

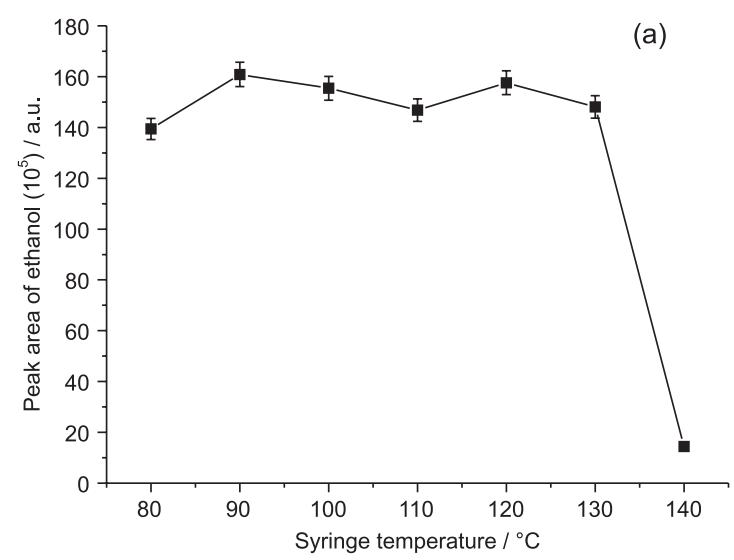

a mass spectrometry (GC/MS) detector in the second dimension. The equipment is connected to each other via the switching device called "heart-cut". ${ }^{22}$ Recent studies have demonstrated the need to use multidimensional equipment to analyze substances directly related to public health. They are substances like pesticides analysis in food ${ }^{23,24}$ and beverages, ${ }^{25}$ drugs of abuse ${ }^{26}$ and medicinal plants. $^{27}$

The influence of the carrier gas flow in the second dimension is very complex because the columns are connected and the valve only transfers all the analyte if the recovery is $100 \%$. For this, there is an ideal pressure selected by the software itself for the transfer to take place. The linear velocity of the carrier gas in the second dimension was $45 \mathrm{~cm} \mathrm{~s}^{-1}$ to ensure $100 \%$ transfer. In a chromatographic column is important observe the film thickness, a $2 \mu \mathrm{m}$ thick column was used in 2D to allow the selective retention of more volatile substances. Tiscione et al..$^{16}$ made a toxicological study using simultaneous analysis of GC-FID and uncontested confirmation of ethanol by GC/MS in blood and urine samples. The method studied in this paper can also evaluate biological samples accurately, as well as other inhalants. According to Tankiewicz et al. ${ }^{4}$ the direct injection for GC analysis is feasible because it is simple and reliable, and multidimensional procedures are tendencies to develop selective, sensitive and stable methodologies for the determination of compounds with different volatilities and polarities.

\section{Analytical validation}

\section{Selectivity}

Figure 2 shows the chromatogram of the syrup under study. The chromatogram generated in MS showed characteristic peaks of the mint essence added in syrup manufacture. They are alcohols and ketones extracted from

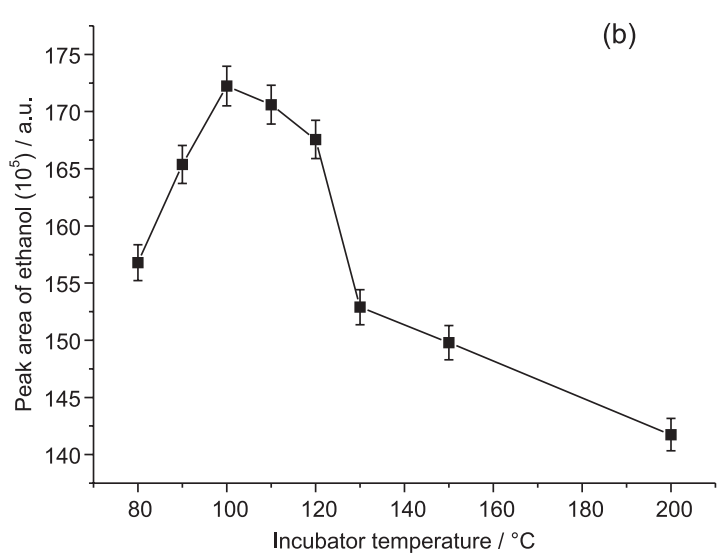

Figure 1. Optimization of sample extraction: (a) syringe temperature; (b) incubator temperature. 

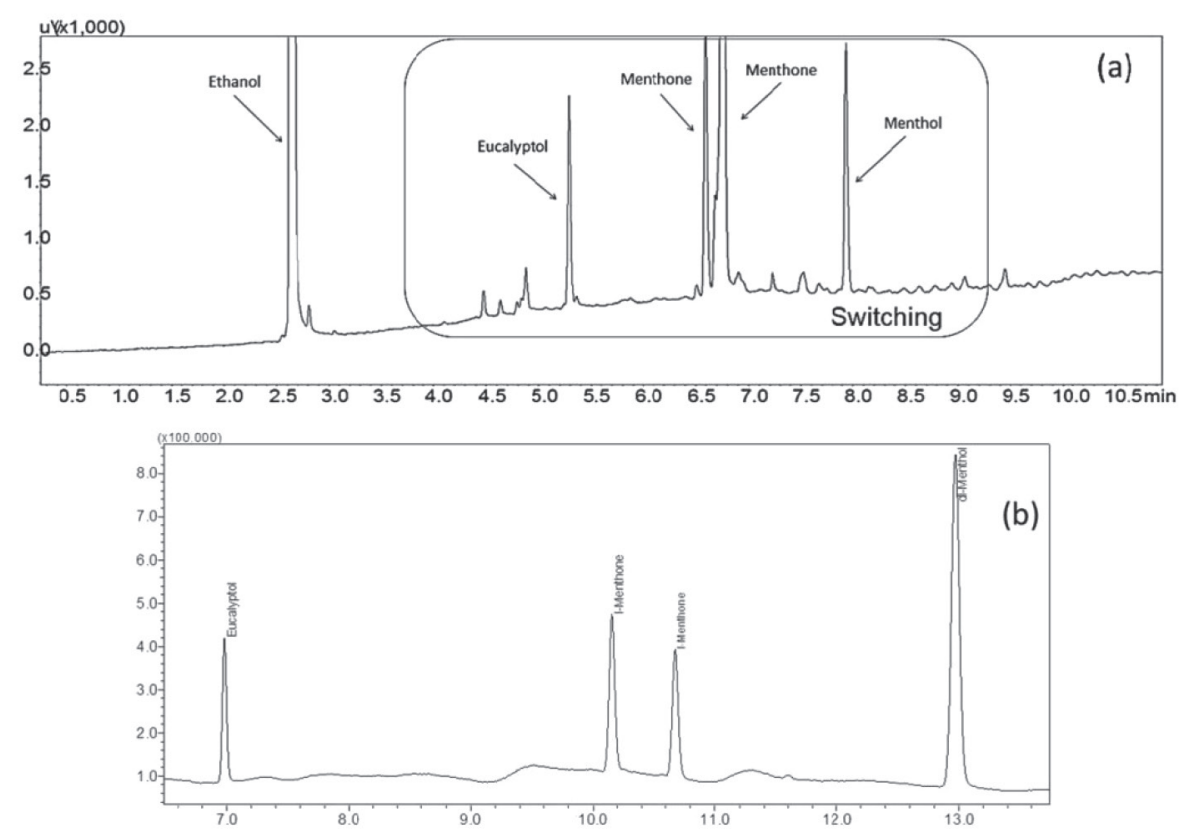

Figure 2. (a) First dimension (GC-FID) chromatogram from headspace analysis of syrup sample extract. (b) Second dimension chromatogram of the main constituents.

the syrup. Mint extract comes from Mentha arvensis. ${ }^{28}$ The composition of the oil is based on the content of organic compounds found, such as menthol, menthone and eucalyptol. Due to the complexity of these flavors, a detailed study of ethanol peak was required. In Figure 2 there is a peak eluted in $2.5 \mathrm{~min}$ with interfering agent. Isopropyl alcohol, detected and unduly separated by GC-FID, is an interfering substances found as a raw material excipient of ranitidine hydrochloride.

Isopropyl alcohol is an excipient ${ }^{29}$ found in the ranitidine and confirmation of its presence in this raw material was performed by injecting a standard with $99.9 \%$ of purity. Comparing the peak of isopropanol generated by ranitidine hydrochloride with the low concentration point used in the calibration curve (1\% ethanol in sorbitol), it was observed that it corresponds to about $10 \%$ of the ethanol peak area. Thereby, it is extremely important that the isopropyl alcohol is suitably separated for the ethanol amount do not be overstimated.

Another component that proved to be interfering in the selectivity analysis was the essence of mint, used in the manufacture of syrups in order to provide pleasant aroma and flavor. This substance showed the presence of ethanol in its composition (see Figure S1 in Supplementary Information (SI) section), which may cause the alcohol content of the syrup to be higher than that anticipated by the pharmaceutical industry. The presence of ethanol in essence may increase the alcoholic content of the syrup by $0.25 \%$. This indicates that multivitamin syrups should not contain the presence of mint essence or any other compound containing ethanol as reported in ANVISA Resolution No. $543^{30}$ which prohibits ethanol in appetite stimulating and growth products, fortifiers, tonics and supplements of iron and phosphor.

Neo et al. ${ }^{14}$ reports that in traditional herbal medicines or essence-based products, ethanol is often used as the extraction solvent to obtain the constituents of the herbs necessary for the efficacy of the product. However, it is important that pharmaceutical companies are concerned about the contribution of ethanol from flavorings and other raw materials to the finished product. In addition, the HS-MDGC/MS proves its ability to separate compounds of similar characteristics at a shorter runtime, small amount of sample and reduction of the consumption of harmful solvents. ${ }^{4}$

\section{Linearity}

Linearity was evaluated using linear regression, at a concentration range from 0.25 to $10.00 \% \mathrm{v} / \mathrm{v}$ of ethanol in sorbitol and water $(0.25,0.50,1.00,2.00,3.00,4.00,6.00$ and $10.00 \%)$. This interval was linear, with linear regression coefficient (r) equal to 0.99976 , which is higher than the established minimum of 0.99 . The analytical curve obtained for the HS-MDGC/MS method was generated from analysis of sorbitol samples and water enriched with ethanol at eight levels of concentration that include the percentage limits established by ANVISA.

The matrix effect was evaluated to find out if there is a difference between preparing the calibration curve at the original matrix (among sorbitol), or over a solvent matrix 
(water). Therefore, three calibration curves were prepared in the same concentration range stipulated by linearity and injected on the same set of analysis. An ANOVA test of statistical significance was applied for each curve and evaluated by the $F$ value (Table 2). According to the values, the impact of the three curves decreased in the order of: water and sorbitol $>$ water $>$ sorbitol, with the matrix water/sorbitol curve being more significant at the $95 \%$ confidence level. Furthermore, due to the higher correlation coefficient ( $r$ ) and because of the chemical composition of greater similarity with most syrup matrices, the water matrix with sorbitol was used for ethanol quantification. A linear model and residuals (SI section) were obtained and show constant error variance. The use of multidimensional chromatography provided greater efficiency in ethanol quantification regardless of the matrix used..$^{5,16}$

Limit of quantification (LOQ) and limit of detection (LOD)

The limit of detection (LOD) of $0.03 \%(\mathrm{v} / \mathrm{v})$ and the limit of quantification (LOQ) of $0.06 \%(\mathrm{v} / \mathrm{v})$ were obtained through the analytical curve, as the concentrations corresponding to 3 and 10 times the baseline noise, respectively. Thereby, the method developed showed higher detection sensitivity of the analyte, ${ }^{5}$ allowing the use of the same equipment for analysis of other drugs or bioanalytical analyses. ${ }^{16}$

\section{Precision and accuracy}

Precision evaluated the dispersion of results between independent, repeated assays of the same sample under defined conditions. The accuracy was evaluated in two different ways, the repeatability evaluating the degree of agreement between the results of successive measurements and the intermediate precision using the same equipment, with analyst and different days. In the different tests performed, the worst result for the repeatability was CV $3.04 \%$ and for the intermediate precision was CV $3.03 \%$ being according to the maximum acceptable value $(5 \%)$ by ANVISA. ${ }^{21}$

Accuracy was calculated as percent recovery of the known amount of ethanol analytical grade $(300 \mu \mathrm{L})$ added to the sample. The developed method presented adequate accuracy, with values ranging from 97.28 to $101.38 \%$, calculated for three concentration levels, low (1\%), medium (3\%) and high (10\%), with low variation in-race and inter-race precision. The efficiency of the proposed method was evaluated by ethanol recovery assays. Recovery values were tested using the Student's $t$-test to confirm the accuracy of the method. Considering the recovery of $100 \%$ of the standard solution was established as a null hypothesis. The $t$-test was applied with $\mathrm{n}-1$ degrees of freedom and more than $99 \%$ confidence. The null hypothesis is acceptable if the absolute value of $t_{\text {calc }}$ (3.68) does not exceed the value of $t_{\text {tab }}$ (4.08). Therefore, it is not possible to affirm the existence of significant differences between the values.

\section{Robustness}

Robustness represents the ability of a method to remain unchanged by small changes in operating and environmental parameters. The GC-2 column temperature change from 56 to $54{ }^{\circ} \mathrm{C}$ generated a coefficient of variation $(\mathrm{CV})$ at a maximum of $3.19 \%$. Another change made in the method was to change the carrier gas from 45 to $50 \mathrm{~cm} \mathrm{~s}^{-1}$, this change also changed the pressure in the split injector and the total flow due to the dependence between these parameters, however, there was no critical variation of values in the ethanol quantification at different concentrations $\left(F \ll<F_{\text {critical }}\right)$. Finally, the extraction parameter was evaluated in order to verify if the increase of the time of extraction would alter the values obtained. The extraction time was increased in $5 \mathrm{~min}$, from 15 to $20 \mathrm{~min}$ of heating in the incubator and the variation of the values did not exceed $3.8 \%$. Using ANOVA, these small changes in the method did not result in statistically significant differences $(p>0.05)$. In addition, the analysis of each variable showed that the $F$ value is much smaller than the critical $F$ value (see SI section). Therefore, the method presents excellent robustness mainly because there is total control between the two dimensions of the equipment. Many studies do not estimate the robustness generating uncertainty regarding the stability of the equipment. ${ }^{5,16,31}$

Table 2. Comparison of linearity in different matrices

\begin{tabular}{lcccc}
\hline \multirow{2}{*}{ Matrix } & \multicolumn{3}{c}{ Linear regression } \\
& \multicolumn{4}{c}{ Linear range: $0.25-10.00 \%(\mathrm{v} / \mathrm{v})$} \\
\cline { 2 - 5 } Sorbitol & Inclination $\left(\times 10^{6}\right)$ & Intercept $\left(\times 10^{5}\right)$ & $\mathrm{r}$ & \multicolumn{2}{c}{$F$-value } \\
Water & 1.61788 & 1.35420 & 0.99752 & 802 \\
Water and sorbitol & 1.58924 & 0.83469 & 0.99873 & 3372 \\
\hline
\end{tabular}

$\mathrm{r}$ : linear regression coefficient. 


\section{Commercial syrups analysis}

After development and validation of the method, HS-MDGC/MS analyses of commercial syrups containing ethanol concentrations ranging from 0.5 to $10 \%$ were applied (Table 3). Despite the fact that there is no Brazilian regulations for reducing ethanol in drugs, the Food and Drug Administration (FDA) has guidelines on maximum ethanol concentrations in oral medication for different age groups. For adults the maximum alcohol concentration is $10 \%$; for children under 12, a maximum of $5 \%$ ethanol is used and for children under 6 the maximum alcohol concentration is $0.5 \% .^{32}$ In Brazil, ethanol content is limited for multivitamin medicines to $0.5 \%$ for children and $2.0 \%$ for adults. ${ }^{30}$

Table 3. Percentage of ethanol found in commercial pharmaceutical forms

\begin{tabular}{lcc}
\hline Code $^{\mathrm{a}}$ & Active principle & Ethanol \pm RSD / \% \\
\hline S1-lot I & ranitidine hydrochloride & $8.34 \pm 0.21$ \\
S1-lot II & ranitidine hydrochloride & $8.83 \pm 0.32$ \\
S2 & levodropropizine & $4.33 \pm 0.14$ \\
S3 & Hedera helix L. (Araliaceae) & $0.07 \pm 0.00$ \\
S4 & calcium phosphate tribasic & $0.94 \pm 0.01$ \\
S5 & polyvitamin & $<\mathrm{LOQ}$ \\
S6 & ciproeptadine hydrochloride & $<\mathrm{LOQ}$ \\
S7 & ranitidine hydrochloride & $2.43 \pm 0.02$ \\
S8 & desloratadine & $<\mathrm{LOQ}$ \\
S9 & dipyrone monohydrate & $<\mathrm{LOQ}$ \\
S10 & guaifenesin & $0.61 \pm 0.01$ \\
S11 & bromopride & $<\mathrm{LOQ}$ \\
S12 & ranitidine hydrochloride & $0.30 \pm 0.00$ \\
S13 & Mikania glomerata & $0.23 \pm 0.00$ \\
S14 & dipyrone monohydrate & $<\mathrm{LOQ}$ \\
S15 & prednisolone sodium phosphate & $0.28 \pm 0.00$ \\
S16 & ascorbic acid & $0.06 \pm 0.00$ \\
S17 & cloperastine phendizoate & $0.53 \pm 0.01$ \\
\hline C00 & repr & \\
\hline
\end{tabular}

${ }^{a}$ Code represents trademarks (the information for each code is in the SI section). RSD: relative standard deviation; LOQ: limit of quantification.

Based on the presented results, it is confirmed that multivitamin complexes in syrup form do not present ethanol in their composition; nearly negligible of $0.03 \%(\mathrm{v} / \mathrm{v})$, complying with Resolution (RE) No. 1 from 2002. The maximum ethanol level for multivitamin complex formulas that need this alcohol to dissolve its components is: for children up to 12 years of age a maximum concentration of $0.5 \%$ and for adult use, a concentration of $2 \%$ ethanol in the formulations. ${ }^{33}$

All syrups evaluated are used for children. However, of the eighteen samples, five presented ethanol quantities much higher than those allowed by ANVISA, namely S1-lot I (8.34\%), S1-lot II (8.83\%), S2 (4.33\%), S4 (0.94\%) and S7 (2.43\%). Others presented values very close to those established by the regulations, such as S10 (0.61\%) and S17 (0.53\%). The remainder presented below-permitted values, being suitable for use in children.

By verifying the applicability of the method, the analysis of 02 samples of a same ranitidine commercial syrup (S1) from different lots indicated that the two samples had ethanol contents above $8.0 \%$ in their composition. In addition, in another 02 samples of the same active principle (ranitidine hydrochloride), a percentage of different ethanol was found. This is because S7 had a percentage of ethanol of $2.43 \%$, a value above the maximum allowed value. The S12 showed an ethanol concentration of $0.29 \%$, which is within the specification of $0.5 \%$ for products of pediatric use and $2.0 \%$ for adult use.

\section{Conclusions}

The headspace process, which covers the extraction and concentration steps, was performed in a total time of $15 \mathrm{~min}$, and the chromatographic separation was obtained in $10 \mathrm{~min}$ in both dimensions. Therefore, in automated systems, it is possible to analyze up to 96 samples per day, ensuring that the proposed method is fast and can be applied in routine laboratory analyzes. The use of a non-polar column in the first dimension allowed the rapid elution of several polar components extracted from the headspace, and the use of polar column chromatography with a high film thickness $(2 \mu \mathrm{m})$ in the second dimension allowed the complete separation of ethanol from other interfering substances, greater reliability for the results obtained. The analytical validation parameters proved the accuracy and precision of the quantitative analyses, with low limits of quantification and detection, wide range of linearity and adequate robustness. The high concentration of ethanol evidenced in some commercial medicated syrup demonstrates the need to increase the quality control of the producing companies, as well as the supervision by ANVISA, making the proposed method a new alternative for quality control of syrups.

\section{Supplementary Information}

Supplementary information (Table S1, Figures S1-S5 and statistic data) is available free of charge at http://jbcs. sbq.org.br as PDF file.

\section{Acknowledgments}

The authors are grateful to FINEP, FUNAPE and CNPq for their financial support and to Capes for Lilian Ribeiro 
Batista's scholarships. The authors are grateful to Geolab pharmaceutical industry for providing the raw materials for this study execution.

\section{References}

1. Lubi, N. C.; Sato, M. E. O.; Gaensly, F.; Rev. Bras. Farmacogn. 2003, 13, 43.

2. Agência Nacional de Vigilância Sanitária (ANVISA); Formulário Nacional da Farmacopéia Brasileira, 2a ed.; ANVISA: Brasília, 2012, p. 224.

3. World Health Organization (WHO); WHO Expert Committee on Specifications for Pharmaceutical Preparations, $46^{\text {th }}$ report; 2012, p. 235.

4. Tankiewicz, M.; Namiesnik, J.; Sawicki, W.; TrAC, Trends Anal. Chem.. 2016, 80, 328.

5. Huzar, E.; Wodnicka, A.; Acta Pol. Pharm. 2013, 70, 41.

6. Mornar, A.; Sertić, M.; Nigović, B.; J. Anal. Chem. 2013, 68, 1076.

7. Zuccotti, G. V.; Fabiano, V.; Expert Opin. Drug Saf. 2011, 10, 499.

8. Christiansen, N.; Arch. Dis. Child. 2015, 100, 101.

9. Roy, M.; Bailey, B.; Chalut, D.; Senécal, P.-E.; Gaudreault, P.; J. Toxicol., Clin. Toxicol. 2003, 41, 155.

10. Jacobson, J. L.; Jacobson, S. W.; Alcohol Res. Health 2002, 26 , 282.

11. Pandya, H. C.; Mulla, H.; Hubbard, M.; Cordell, R. L.; Monks, P. S.; Yakkundi, S.; McElnay, J. C.; Nunn, A. J.; Turner, M. A.; Eur. J. Pediatr. 2016, 175, 841.

12. Village, E. G.; Pediatr. 1984, 73, 405.

13. Taniguchi, C.; Guengerich, F. P.; Princípios de Farmacologia-A Base Fisiopatológica da Farmacologia; $3^{\text {rd }}$ ed.; Golan, D. E.; Tashjian Jr., A. H.; Armstrong, E. J.; Armstrong, A. W., eds.; Guanabara Koogan: Rio de Janeiro, 2018, p. 952.

14. Neo, M. S.; Gupta, S. M.; Khan, T. M.; Gupta, M.; Pharmacogn. J. 2017, 9, 821.

15. Wang, M.; Choong, Y.; Su, N.; Lee, M.; J. Food Drug Anal. 2003, 11, 133.

16. Tiscione, N. B.; Alford, I.; Yeatman, D. T.; Shan, X.; J. Anal. Toxicol. 2011, 35, 501.

17. Alves, E. G.; Silva, L. M. A.; Araújo, N. V. P.; Alves, E. G.; Lião, L. M.; Alcantara, G. B.; J. Pharm. Biomed. Anal. 2018, 153, 29.

18. Peters, F. T.; Drummer, O. H.; Musshoff, F.; Forensic Sci. Int. 2007, 165, 216.
19. Ravichandran, V.; Shalini, S.; Sundram, K. M.; Rajak, H.; Int. J. Pharm. Pharm. Sci. 2010, $2,18$.

20. Ribani, M.; Bottoli, C. B. G.; Collins, C. H.; Jardim, I. C. S. F.; Melo, L. F. C.; Quim. Nova 2004, 27, 771.

21. Agência Nacional de Vigilância Sanitária (ANVISA); Resolução da Diretoria Colegiada (RDC) No. 166, de 24/07/2017, Dispõe sobre a Validação de Métodos Analíticos e dá outras Providências; Diário Oficial da União (DOU): Brasília, No. 141, de 25/07/2017.

22. Hiraoka, T.; Asakawa, M.; Wada, T.; Furukawa, M.; Terai, Y.; Am. Lab. 2009, 41, 40.

23. Paravisini, L.; Prot, A.; Gouttefangeas, C.; Moretton, C.; Food Chem. 2015, 167, 281.

24. del Castillo, M. L. R.; Rodríguez-Valenciano, M.; Flores, G.; Blanch, G. P.; LWT - Food Sci. Technol. 2019, 99, 283.

25. Wen, Y.; Ontañon, I.; Ferreira, V.; Lopez, R.; Food Chem. 2018, 255, 235.

26. Putz, M.; Piper, T.; Casilli, A.; Radler, F.; Neto, D. A.; Pigozzo, F.; Thevis, M.; Anal. Chim. Acta 2018, 1030, 105.

27. Sciarrone, D.; Giuffrida, D.; Rotondo, A.; Micalizzi, G.; Zoccali, M.; Pantò, S.; Donato, P.; Rodrigues-das-dores, R. G.; Mondello, L.; J. Chromatogr. A 2017, 1524, 246.

28. Monteiro, R.; Hortic. Bras. 2013, 31, 178.

29. Fabiano, V.; Mameli, C.; Zuccotti, G. V.; Pharmacol. Res. 2011, 63,362 .

30. Agência Nacional de Vigilância Sanitária (ANVISA); Resolução (RE) No. 543/01, Proibição da Presença de Etanol em todos os Produtos Fortificantes, Estimulantes de Apetite e Crescimento, e Complementos de Ferro; Diário Oficial da União (DOU): Brasília, de 20/04/2001.

31. Kudale, A.; Mulani, K.; Toche, R.; Chem. Sci. Trans. 2016, 5 , 248.

32. U.S. Food and Drug Administration (FDA); 21CFR328, Over the Counter Drug Products Intended for Oral Ingestion that Contain Ethanol; U.S. Government Publishing Office: Rockville, 2017.

33. Agência Nacional de Vigilância Sanitária (ANVISA); Resolução (RE) No. 01, de 25/01/2002; Complementa o Disposto na Resolução (RE) No. 543/01; Diário Oficial da União (DOU): Brasília, No. 19, de 28/01/2002.

Submitted: September 19, 2018 Published online: August 15, 2019 